\title{
IMPACTOS DO PIBID SOBRE ATUAÇÃO DE PROFESSORES EGRESSOS DO CURSO DE LICENCIATURA EM EDUCAÇÃO ESPECIAL
}

\author{
IMPACTOS DEL PIBID SOBRE LA ACTUACIÓN DE PROFESORES EGRESOS DEL \\ CURSO DE PROFESORADO EN EDUCACIÓN ESPECIAL
}

\author{
PIBID IMPACTS OVER THE WORK OF TEACHERS EGRESS FROM SPECIAL \\ EDUCATION UNDERGRADUATE COURSE
}

\author{
Cariza de Cássia SPINAZOLA ${ }^{1}$ \\ Márcia Duarte GALVANI ${ }^{2}$
}

RESUMO: O Programa Institucional de Bolsa de Iniciação à Docência (PIBID) destaca-se por oportunizar experiências de docência aos alunos dos cursos de licenciaturas. Nesse sentido, o objetivo da pesquisa foi identificar os impactos que o PIBID da UFSCar/subprojeto do curso de licenciatura em Educação Especial tem ou teve sobre a prática docente na percepção de educadores especiais em seus anos iniciais de carreira. Participaram da pesquisa 19 egressos do curso de Licenciatura em Educação Especial da Universidade Federal de São Carlos (UFSCar), que foram divididos em dois grupos, sendo o G1 formado por 10 egressos que participaram do PIBID e o G2 formado por 9 egressos que não participaram do PIBID. $\mathrm{O}$ estudo caracterizou-se como descritivo e o instrumento utilizado para coleta de dados consistiu em um questionário com perguntas abertas. O procedimento de coleta foi por meio do contato com os coordenadores do curso de Licenciatura em Educação Especial e coordenadores do PIBID/subprojeto do curso de Licenciatura em Educação Especial da UFSCar. A análise dos dados foi realizada por meio da análise de conteúdo. Os resultados indicaram que ambos os grupos revelaram aspectos positivos em diversos projetos e programas, porém no G1 percebe-se que os professores destacaram que as experiências vivenciadas pelo acesso ao PIBID são importantes em suas práticas atuais, assim como a proposta do trabalho colaborativo, o qual não apareceu no G2. Em relação ao G2, notou-se o estágio como a experiência relevante para atuação, assim como o aprendizado no cotidiano e o aprendizado durante as aulas.

PALAVRAS-CHAVE: Educação especial. PIBID. Prática docente.

RESUMEN: El Programa Institucional de Beca de Iniciación a la Docencia (PIBID) se destaca por dar la oportunidad de experiencias en docencia a los alumnos de los cursos de profesorados. En este sentido, el objetivo de la investigación fue identificar los impactos que el PIBID de la UFSCar/subproyecto del curso de profesorado en Educación Especial ejerce o ejerció a la práctica docente en la percepción de educadores especiales en sus años iniciales de carrera. Participaron de la investigación 19 egresos del curso de Profesorado en

${ }^{1}$ Universidade Federal de São Carlos (UFSCar), São Carlos - SP - Brasil. Doutoranda do Programa de PósGraduação em Educação Especial. ORCID <https://orcid.org/0000-0001-5197-5834>. E-mail: carizaspinazola@gmail.com

${ }^{2}$ Universidade Federal de São Carlos (UFSCar), São Carlos - SP - Brasil. Prof. Dra. Adjunta do Departamento de Psicologia. ORCID <https://orcid.org/0000-0003-1092-746X>. E-mail: marciaduar@yahoo.com.br 
Educación Especial de la Universidad Federal de São Carlos (UFSCar), que fueron divididos en dos grupos, siendo el G1 formado por 10 egresos que participaron del PIBID y el G2 formado por 9 egresos que no participaron del PIBID. El estudio fue caracterizado como descriptivo y el medio utilizado para la recopilación de los datos se constituyó en un cuestionario con preguntas abiertas. El procedimiento de recopilación se dio por medio del contacto con los coordinadores del curso de Profesorado en Educación Especial de la UFSCar. El análisis de los datos se realizó por medio del análisis de contenido. Los resultados indicaron que ambos grupos revelaron aspectos positivos en distintos proyectos y programas, pero en el G1 se percibe que los profesores destacaron que las experiencias vividas por el acceso al PIBID son importantes en sus prácticas actuales, así como la enseñanza colaborativa, la cual no apareció en el G2. Con relación al G2, fue percibida la pasantía como la experiencia relevante para actuación, así como el aprendizaje en el cotidiano y el aprendizaje durante las clases.

PALABRAS CLAVE: Educación especial. PIBID. Práctica docente.

ABSTRACT: Scholarship for Teaching Initiation Institutional Program (PIBID) outstands for giving opportunity of teaching experience to undergraduate students. In this sense, the purpose of this research was to identify the impacts that UFSCar PIBID subproject of Special Education undergraduate course has or had over the teaching practice, according to the perception of special educators in their first years of career. 19 egresses majored in Special Education at Federal University of São Carlos (UFSCar) participated of this research. They were divided in two groups: G1, composed by 10 people who were members of PIBID and G2, composed by 9 people who were not members of PIBID. The study was characterized as descriptive and the tool used for data collection consisted of a questionnaire with open questions. The collection procedure was done through contact with the coordinators of Special Education undergraduate course and coordinators of UFSCar PIBID subproject. The data analysis was performed through content analysis. The results indicated that both groups demonstrated positive aspects in many projects and programs. However, in G1 it is possible to notice that the teachers highlighted that the experiences held through the access to PIBID are important in their current practice, as well as the collaborative teaching, which was not present in G2. About G2, it was possible to notice the internship experience as relevant to their practice, as well as daily learning during classes.

KEYWORDS: Special education. PIBID. Teaching practice.

\section{Introdução}

O Programa Institucional de Bolsa de Iniciação à Docência (PIBID) é um programa que tem como objetivo contribuir para formação inicial de licenciandos para futura atuação na Educação Básica, incentivando o magistério em escolas públicas, melhoria do nível da qualidade da formação inicial nos cursos de licenciatura no ensino superior, oportunidades de experiências e práticas docente, por meio da inserção dos licenciandos na escola pública e contribuições no âmbito da relação teoria e prática (PORTARIA CAPES, 2010). Além do 
aperfeiçoamento dos discentes e professores da rede, o PIBID visa à melhoria da educação básica brasileira (BRASIL, 2010).

O PIBID oferece bolsas aos alunos que realizam atividades pedagógicas nas escolas públicas de educação básica, proporcionando experiências que incentivem a relação entre teoria e prática (PORTARIA CAPES, 2016). A garantia de bolsas é regulamentada pela Lei n. 11.273/06 que autoriza o Fundo Nacional de Desenvolvimento da Educação (FNDE) e a Coordenação de Aperfeiçoamento de Pessoal de Nível Superior (CAPES) a conceder bolsa de estudo ou pesquisa a programas que visem contribuir com a formação de professores. Desse modo, todo aluno matriculado regularmente em algum curso de licenciatura de nível superior pode integrar o PIBID, desde que este esteja implementado no curso (BRASIL, 2010).

Segundo Gatti (2013), iniciativas que favorecem a formação inicial de professores vêm se disseminando, tendo como foco principal os personagens centrais no processo educacional. Para a autora, estes programas surgem devido à constatação da necessidade de maior qualidade na formação inicial dos alunos nas universidades, assim como no ensino das escolas de educação básica.

Buscando mostrar sobre a efetivação do PIBID, Verdum (2014) realizou uma pesquisa que objetivou apresentar e discutir quais os objetivos e resultados de estudos sobre o PIBID. Para responder aos objetivos, foi realizado um levantamento no banco de Teses e dissertações da Capes e nos trabalhos apresentados na XVI Reunião do Endipe de 2012. Os resultados mostraram que os 14 trabalhos encontrados no banco de teses e dissertações apontaram aspectos positivos do PIBID, principalmente com relação à contribuição na sua formação no que diz respeito à reflexão da prática docente, relação entre instituição formadora e unidade escolar. Na XVI Reunião do Endipe de 2012 foram encontrados 46 trabalhos que em sua maioria revelaram sobre avaliação dos projetos e ações desenvolvidas, e um número menor de estudos relacionados à concepção do professor formador. Esse estudo destacou que se torna importante olhar os impactos que o programa assumiu para as IES e nas escolas públicas, pois a forma "como cada um vive a profissão de professor é tão mais importante do que as técnicas que aplica ou os conhecimentos que transmite; os professores constroem a sua identidade por referência a saberes práticos e teóricos" (NÓVOA, 1995, p. $33)$.

Visto a importância de se olhar os impactos do PIBID, a pesquisa de Santana (2015) teve como objetivo analisar as repercussões do PIBID da Universidade do Recôncavo da Bahia (UFRB) na iniciação profissional docente dos egressos deste programa, mais especificamente, na dimensão da profissionalização. Participaram do estudo 14 professores da 
rede municipal de Amargosa; entre estas 7 eram egressas do PIBID e 7 não fizeram parte do programa. Os dois grupos contaram com professoras formadas pela UFRB. A formação inicial das participantes era em pedagogia e matemática. A técnica utilizada para coleta de dados foi uma entrevista semiestruturada. Os resultados apontaram muitos aspectos semelhantes no início da carreira dos dois grupos. Porém percebeu-se na comparação entre os grupos de professoras que aquelas que foram bolsistas do PIBID demostraram ter maiores habilidades para controlar e disciplinar a turma, menores dificuldades com relação a metodologias de ensino e avaliação e que o PIBID causou impactos positivos nos anos iniciais de carreira.

Portanto, investigar uma instituição e uma área específica relacionada às influências que o PIBID assume em uma dada realidade é importante para revelar problemáticas e pontos positivos acerca da formação inicial dos licenciandos. Nesse âmbito, o foco deste estudo é o PIBID/UFSCAR, subprojeto do curso de Licenciatura em Educação Especial.

Nessa perspectiva, o PIBID/Educação Especial visa essa inserção dos alunos bolsistas nas escolas por meio da colaboração entre professor da sala regular e licenciando, a fim de beneficiar a escolarização e consequentemente a inclusão escolar dos alunos público-alvo da educação especial (PAEE) nas escolas, por meio de adaptações adequadas a cada aluno. Além disso, preconiza oferecer experiências aos licenciandos do curso de Licenciatura em educação especial, no sentido de perceberem que a formação é composta pelas vivências e embates da prática e suas necessidades (PIBID/EDUCAÇÃO ESPECIAL, 2013).

Duarte, Campos e Vilaronga (2014) objetivaram analisar as experiências relatadas por bolsistas do PIBID da Educação Especial da UFSCar em formação inicial mediante atividades no espaço escolar de duas instituições. A pesquisa caracterizou-se como exploratória descritiva. A análise dos dados foi feita por meio de categorização dos relatos dos bolsistas. Tais relatos foram retirados dos portfólios dos licenciandos. Os resultados evidenciaram que os alunos descreveram aspectos positivos com relação ao PIBID, principalmente frente à construção da relação entre teoria e prática e às parcerias colaborativas como um fator de aprendizagem da formação inicial. O estudo contribuiu para mostrar que a colaboração entre bolsistas e professores regentes impulsiona mostrar um novo paradigma dentro do contexto escolar.

A pesquisa desenvolvida por Batista, Duarte e Campos (2016) teve como objetivo apresentar as atividades resultantes do trabalho de uma bolsista do PIBID/educação especial da UFSCar. Participou do estudo uma professora do $2^{\circ}$ do ensino fundamental de uma escola municipal, que tinha em sua sala um aluno com síndrome de Down (SD). Os resultados 
mostraram que o trabalho da bolsista inicialmente foi de observação acerca das práticas dos professores, conteúdos e metodologias, tanto com relação ao aluno com SD quanto os demais. As disciplinas que a bolsista acompanhou foram: Português, Matemática e Ciências, e em sua maioria as atividades eram voltadas à leitura, escrita, interpretação e resolução de cálculos. $\mathrm{O}$ relato do estudo demostra que durante o ano a parceria entre bolsista e professora foi se estabelecendo, de forma que ambas planejavam possibilidades de adaptações para o aluno alvo, o que resultou em avanços com relação à escolarização do mesmo. Essa parceria entre licencianda e professora favoreceu o processo de formação inicial da discente, assim como oportunizou avanços relacionados ao aluno, apoiando a inclusão escolar em determinada realidade.

Nota-se que a maioria dos estudos relacionados ao PIBID da Educação Especial tem por finalidade mostrar e descrever as práticas pedagógicas e atividades desenvolvidas pelos bolsistas durante suas trajetórias nas escolas, assim como mostrar a percepção dos respectivos enquanto estes fazem parte da equipe do PIBID (DUARTE; CAMPOS; VILARONGA, 2014; MENDES; MESSERSCHMIDT; PEREIRA; SILVA; MENEZES, 2014; BERTÃO, DUARTE; CAMPOS, 2015; BATISTA; DUARTE; CAMPOS, 2016; CARVALHO; FUKUARA; CAMPOS; DUARTE, 2016; LEVI; CAMPOS; GALVANI, 2016; KHALED; CAMPOS; DUARTE, 2016). Buscando ampliar o conhecimento acerca do PIBID da Educação Especial e suas influências sobre a formação inicial de educadores especiais surgiu uma questão que impulsionou a problemática desta pesquisa, sendo esta: Quais as contribuições que o PIBID da Educação Especial proporcionou aos egressos em suas práticas pedagógicas dentro da escola e com os alunos?

Partindo dessa premissa, e pensando nos objetivos do PIBID, torna-se importante analisar os impactos e influências que o programa tem sob os egressos nos anos inicias de suas carreiras a partir da comparação entre dois grupos, buscando dessa forma ampliar as pesquisas que envolvem o PIBID e a Educação Especial, assim como mostrar a relevância dos demais programas, visto que o processo de inclusão escolar garante que os alunos PAEE tenham garantido sua matrícula na rede regular de ensino.

Sendo assim, o objetivo da pesquisa foi identificar os impactos que PIBID da UFSCar/subprojeto do curso de licenciatura em Educação Especial tem ou teve sobre a prática docente na percepção de educadores especiais em seus anos iniciais de carreira, a partir da comparação ente egressos que participaram do PIBID e egressos que não participaram. 


\section{Método}

Este estudo caracterizou-se como descritivo, pois analisou uma característica de determinado grupo, objetivando descrever opiniões, atitudes, práticas e crenças de uma determinada população (GIL, 2002).

\section{Participantes}

Participaram da pesquisa 19 egressos do curso de licenciatura em Educação Especial da UFSCar, que foram divididos em dois grupos (vide tabela 1). As participantes são do gênero feminino, a média de idade é de 29,2 anos, variando de 22 a 51. Assim, com a finalidade de caracterizar a formação das participantes, a Tabela 1 apresenta informações sobre a formação, participação em projetos e atuação profissional.

Tabela 1 - Caracterização dos participantes

\begin{tabular}{|c|c|c|}
\hline Participantes & Projetos que participou & Atuação profissional \\
\hline \multicolumn{3}{|c|}{ Professores egressos que participaram do PIBID } \\
\hline P1 & PIBID & Instituição de Educação Especial \\
\hline $\mathbf{P 2}$ & \multicolumn{2}{|l|}{$\begin{array}{l}\text { Monitoria } \\
\text { Projeto de extensão }\end{array}$} \\
\hline P3 & Liga da leitura PIBIC PIBID & Sala de Recursos -SRM \\
\hline $\mathbf{P 4}$ & PIBID PIBIC & Sala de Recursos -SRM \\
\hline P5 & PIBID & Instituição de Educação Especial \\
\hline P6 & PIBID & Instituição de Educação Especial \\
\hline P7 & $\begin{array}{l}\text { PIBID } \\
\text { PIBIC }\end{array}$ & Interprete de Libras \\
\hline P8 & PIBIB & Sala de Recursos - SRM \\
\hline P9 & $\begin{array}{c}\text { PIBID } \\
\text { Projeto de extensão }\end{array}$ & Sala de Recursos - SRM \\
\hline P10 & PIBID & Sala de Recursos - SRM \\
\hline \multicolumn{3}{|c|}{ Professores egressos que não participaram do PIBID } \\
\hline P11 & Projeto de monitoria & Sala de Recursos - SRM \\
\hline P12 & Não participou de projetos & Sala de Recursos - SRM \\
\hline P13 & $\begin{array}{c}\text { PIBIC } \\
\text { Projeto de extensão }\end{array}$ & $\begin{array}{c}\text { Aluna de pós-graduação. Atuou em } \\
\text { sala de recursos - SRM }\end{array}$ \\
\hline P14 & Não participou de projetos & $\begin{array}{c}\text { Empregada doméstica. Atuou em sala } \\
\text { de recursos-SRM }\end{array}$ \\
\hline P15 & $\begin{array}{l}\text { Projeto de extensão Iniciação } \\
\text { científica }\end{array}$ & Professora Bilíngue de Libras \\
\hline P16 & Projetos de extensão & $\begin{array}{c}\text { Aluna de pós-graduação. Atuou em } \\
\text { instituições especializadas e realizando } \\
\text { acompanhamento particular }\end{array}$ \\
\hline P17 & $\begin{array}{l}\text { Projeto de extensão } \\
\text { Monitoria PIBIC }\end{array}$ & Sala de Recursos -SRM \\
\hline P18 & Não participou de projetos & Sala de Recursos -SRM \\
\hline P19 & Projeto de extensão & Sala de Recursos -SRM \\
\hline
\end{tabular}

Fonte: Elaborado pelas autoras 


\section{Aspectos éticos}

A presente pesquisa foi aprovada pelo Comitê de Ética em Pesquisa em Seres Humanos da Universidade Federal de São Carlos (CAAE: 72770117.9.0000.550). Destaca-se que o TCLE foi disponibilizado on-line para os participantes por meio do acesso ao link do questionário formulado por meio do GoogleDocs.

\section{Instrumento para os participantes}

O instrumento de coleta de dados foi um questionário baseado do estudo de Santana (2015) e adaptado para esta pesquisa. Tal instrumento foi dividido em três categorias que englobavam diferentes aspectos: (a) caracterização do participante; (b) informações sobre a graduação; (c) experiência e atuação profissional em diferentes aspectos.

\section{Procedimento de coleta de dados}

Para realização do convite a pesquisadora estabeleceu contato com as coordenadoras do curso de Licenciatura em Educação Especial e do PIBID da Educação Especial para solicitar a lista com nomes e e-mails dos egressos das turmas de 2010, 2011, 2012 e 2013. A segunda etapa consistiu no encaminhamento de um e-mail explicando os objetivos e convidando os egressos a participarem da pesquisa.

\section{Local de coleta de dados}

A coleta de dados com os participantes foi on-line, na qual os mesmos responderam ao instrumento acessando o link com o formulário elaborado por meio do GoogleDocs que foi disponibilizado via e-mail.

\section{Procedimento de análise dos dados}

Os dados coletados por meio do questionário foram qualitativos e estão sendo analisados e comparados entre G1 (professores egressos que participaram do PIBID) e G2 (professores egressos que não participaram do PIBID) por meio da análise de conteúdo, na qual os dados são desmembrados em unidades de conteúdo e categorização (FRANCO, 2003). 


\section{Resultados e discussões}

Os resultados comparativos foram apresentados e discutidos por meio de três tópicos: (a) G1: professores egressos que participaram do PIBID, (b) G2: professores egressos que não participaram do PIBID e (c) comparação entre G1 e G2.

\section{G1: professores egressos que participaram do PIBID}

No que se refere às contribuições dos programas/projetos na formação inicial dos professores egressos do G1, identificou-se que P1, P2, P3, P6, P7 e P10 destacaram que o PIBIB colaborou em suas práticas e atuações docentes, como pode ser identificado em alguns relatos ilustrativos:

Forneceram possibilidades de experimentar situações das quais hoje preciso atuar. Oferece uma certa segurança, pois já passamos por situações parecidas (P1).

Sim, contribuiu principalmente para o exercício da prática docente em ambiente escolar (P2).

O PIBID me deu subsídios para a prática na sala de recursos, já que foi através do programa que tive meu primeiro contato com esse tipo de sala, que atualmente é meu campo de atuação (P3).

Sim, aprendi práticas muito importantes para minha atuação profissional (P7).

Os relatos apontaram que a prática e conhecimento da profissão durante a participação no programa trazem subsídios para os egressos, que se sentem mais seguros quando iniciam suas carreiras. O estudo de Ambroseti, Nascimento, Almeida, Calil e Passos (2013) explicita, baseado na percepção de bolsistas, como o PIBID contribui na construção da profissionalidade, por meio da reflexão do aprender a ser professor. Desse modo, percebe-se que seja já em exercício da profissão ou durante a formação, o PIBID favorece o crescimento profissional e desencadeia uma gama maior de vivências durante o processo formativo.

Já para P3, P5, P9 e P10 as contribuições foram acerca do trabalho colaborativo, conforme falas ilustrativas:

O PIBID, por exemplo, contribuiu para que eu pensasse no coletivo e não somente no aluno PAEE; a trabalhar com outros parceiros, percebendo que o trabalho em equipe é fundamental na educação especial (P3)

Sim, bastante pensando no regime escolar para o trabalho colaborativo (P5). 
No PIBID, foi possível verificar a rotina escolar e como se dá a inclusão de um aluno PAEE dentro da sala de aula regular visando o ensino colaborativo entre o professor e o educador especial, tarefa essa que nem sempre é tão fácil de ser implantada (P9).

A experiência em acompanhar a evolução dos alunos, participar conjuntamente com o professor regular, organizar eventos para discussão e o apoio semanal de estudos e reuniões, foram uma base sólida para o desenvolvimento do projeto (P10).

Um dos objetivos do PIBID/Educação Especial é a colaboração entre professor da sala regular e licenciando (PIBID/EDUCAÇÃO ESPECIAL, 2013). Segundo Mendes, Almeida e Toyoda (2011), “o ensino colaborativo ou coensino é um modelo de prestação de serviço de Educação Especial no qual um educador comum e um educador especial dividem a responsabilidade" (2011, p. 84). Portanto, por meio do PIBID os alunos da Educação Especial podem ter experiências colaborativas em sala de aula, que serão importantes durante o exercício da profissão.

Dando continuidade nessas questões, na categoria avaliação dos programas/projetos foi possível identificar os pontos positivos do PIBID na percepção dos egressos do G1. Para P2, P3, P4, P5, P9, P10 o programa foi avaliado como importante na questão da identidade do professor, além de favorecer o contato direto com o campo de atuação profissional, como ilustram os relatos:

Importante para o desenvolvimento da minha identidade como professora, visto poder participar de todos os âmbitos que envolvem essa profissão (P2)

Possibilita uma vivência real no ambiente escolar, mostrando o dia a dia do "ser professor" bem como suas diversas atribuições: se apropriar da teoria, planejar aulas, pensar nas adaptações que essa aula exige para que o aluno PAEE possa aproveitá-la da melhor forma (P4).

E é um marco de direcionamento na profissão, pois é ali na pratica que decidimos se é isso que realmente queremos (P5).

Avalio como positivo e muito importante na trajetória acadêmica de licenciandos, conhecendo o "chão da escola" (P10).

Assim como percebido em outras pesquisas (SANTOS, 2013; RODRIGUES; SILVA, 2015), o programa proporcionou vivenciar sentimentos e práticas antecipadas da profissão antes dos estágios obrigatórios, oportunizando aos alunos de graduação experienciar os desafios e caracteristicas da profissão dentro do contexto escolar.

Para as participantes P1, P6, P7 e P8, o PIBID foi avaliado como sendo um programa bom. Como relato ilustrativo demonstra: 
Projeto importante e bem orientado (P1)

Projeto bom, aprendizado que vai além da academia (P6)

Sobre as influências das experiências vivenciadas na graduação nas práticas docentes do G1, P2 e P3 destacaram o PIBID como um programa importante nas práticas e estratégias que exercem atualmente na profissão.

Dentre as minhas experiências no PIBID sempre era necessário planejar atividades que contemplassem o conteúdo, mas de forma atrativa $e$ funcional, acredito que esse seja uma grande influência no meu trabalho atualmente, estou sempre buscando formas de apresentar o ensino de maneira que o aluno se interesse e aprenda com significado (P2).

As experiências que mais contribuíram foram o PIBID e o PIBIC, o primeiro porque me deu noção da pratica em sala de aula e o segundo porque me deu fundamentação teórica para a prática (P3).

A Portaria Capes, n. 46 (2016), indica que um dos objetivos do PIBID é criar oportunidades de participação e execução de práticas docentes, metodológicas e estratégias de ensino, com a finalidade de apoio para superação dos desafios e dificuldades dos alunos. Nesse ponto, percebe-se que, por exemplo, P2 coloca em prática atualmente estratégias docentes que respondam às necessidades de seus alunos.

Os professores P1, P5, P6, P8, P9, P10 destacaram as experiências e habilidades exigidas durante a graduação relacionadas às disciplinas e práticas dos professores. Percebese que apesar de destacarem o PIBID, o G1 também demostrou que outras oportunidades são relevantes para formação e atuação docente.

Sim! Estas experiências foram fundamentais para minha formação pessoal e profissional. Conhecer práticas, recursos, tecnologia, estudos de caso. (P1).

Acho de como se portar no ambiente de trabalho, em adaptações de materiais e atividades (P5).

Sim, PIBID, confecção de materiais, aulas, vivências (P6)

Sim. Durante as conversas com as professoras, a prática docente e coerente de cada uma delas, foram exemplos de postura (P10)

Percebeu-se que para além do PIBID, os professores reconhecem que as práticas vivenciadas durante a graduação foram pontos que colaboraram para suas atuações, o que identifica que todas as oportunidades oferecidas durante a graduação se complementam e tornam-se relevantes. 
De modo geral, percebe-se que o G1 descreveu pontos positivos que o PIBID proporcionou e que influenciam em suas práticas docentes até os dias atuais. Este dado nos indica a importância que o programa assume, principalmente por ter como objetivo a melhoria da qualidade da educação.

\section{G2: professores egressos que não participaram do PIBID}

Com relação às contribuições dos programas/projetos na formação inicial dos professores egressos do G2, destaca-se a relevância da teoria para aplicação da prática, como mencionado por P11 e P12.

Sim, troca de experiências e bases teóricas para lidar com a realidade (P11)

Sim, bastante. Me permitiu ver a aplicabilidade da teoria, ou seja, colocar em prática tudo o que estudava (P12).

Os participantes P15, P16, P17 e P18 destacaram as contribuições de programas como monitoria, PIBIC e extensão, como pode ser visto em duas falas ilustrativas:

No projeto de extensão Brinquedoteca Para Todos aprendi diversos materiais adaptados que hoje posso usar na minha prática. Com a bolsa de iniciação científica do ONEESP adquiri experiência pois pude entender melhor como funcionava na prática a Educação Especial com o relato de outros professores da área no que se refere a formação do professor, organização do trabalho pedagógico e avaliação dos alunos PAEE nas escolas (P15).

As monitorias contribuem para a formação no âmbito da responsabilidade em informar alunos sobre os conteúdos das aulas, estar nas aulas, acompanhar os professores e estar atento as aulas ministradas pois, as possíveis dúvidas dos alunos são feitas para os monitores. A postura frente aos alunos que nos contatam para obter informações e auxílios sobre a disciplina, os meios pelos quais pensamos e fazemos na hora de explicar conteúdos sobre a disciplina. O PIBIC contribuiu para a minha formação no sentido que mudou minha visão frente aos acontecimentos, pensar os motivos, o contexto, o que importa não só para mim, mas principalmente ao outro, hoje meus alunos, e também na lida com os colegas de profissão (P17).

Um estudo desenvolvido por Bridi (2010) destaca as contribuições das iniciações científicas na formação inicial de universitários e indicam que para os graduandos a participação em programas de iniciação científica (IC) se expande para além do ser pesquisador, trazendo conhecimento cultural, intelectual e moral. Estes dados complementam os relatos dos professores egressos, que demostraram que a IC foi além da percepção de conhecimento para pesquisa. 
No quesito avaliação do projeto/programa que participou, P13, P15 e P16 relataram como importantes para formação, trazendo benefícios:

Ambos os projetos foram de extrema importância para todos os envolvidos, trouxe muitos benefícios para todos (P13).

Excelente, nos dois projetos pude me envolver com os docentes, com a realidade da vida acadêmica e tais experiências contribuíram para minha formação enquanto profissional que sou hoje (P15).

Acredito que foram projetos bem interessantes para minha formação (P16).

Ao que se refere às influências das experiências vivenciadas na graduação nas práticas docentes do G2, o estágio obrigatório foi mencionado por P13, P14, P15, P17, P18 como pode ser identificado abaixo:

Com certeza. Fiz estágio em uma escola bilíngue e foi lá que pude me apaixonar mais pela educação de surdos e me deu base para iniciar o trabalho que exerço hoje (P15).

Sim, as experiências de estágio, tanto da prática como das orientações me influenciam, tanto nas práticas pedagógicas, assim como nas tomadas de decisões relacionadas a encaminhamentos par diagnóstico, no momento de conversar e lidar com os pais de alunos e lidar com os demais professores (P17).

Sim, toda experiência que tenho adquiri nos estágios, principalmente com alunos com Deficiência Intelectual (P18).

O estágio supervisionado durante a graduação deve ser valorizado como um momento de formação, que garante a vivência e a relação entre teoria e prática no contexto de atuação futura do licenciando (RIBEIRO; ARAÚJO, 2017; PIMENTA; LIMA, 2009). No curso de licenciatura em Educação Especial, o objetivo é que os alunos conheçam as práticas pedagógicas inclusivas em diferentes etapas de ensino e em instituições especializadas, a fim de que intervenham por meio de práticas pedagógicas de apoio e suporte no contexto educacional em que estão inseridos (PROJETO POLÍTICO PEDAGÓGICO DO CURSO DE LICENCIATURA EM EDUCÃO ESPECIAL, 2012). Nota-se que para o propósito de desenvolvimento de habilidades e aprendizado no contexto de estágio é algo que os egressos se baseiam e identificam suas contribuições no exercício atual de suas profissões.

P11 e P12 apontaram que os principais aprendizados são no cotidiano:

Acredito que possam ter me dado a base, mas meus maiores aprendizados foram colocando a mão na massa e aprendendo no dia a dia (P11). 
Acredito que a graduação ajudou muito, porém a prática foi totalmente diferente da teoria, pois as estratégias utilizadas muitas vezes é particular de aluno para aluno (P12).

Além disso, P16 e P19 destacaram as experiências durante as aulas:

Com certeza, os estudos de caso durante as aulas contribuíram muito. Me lembro que era complicado durante as aulas pensar em estratégias específicas para cada estudo de caso, porém ao ver as estratégias utilizadas também pelos meus colegas eu podia estar aprimorando a minha própria (P16).

Sem dúvidas. Experiências em sala de aula, em troca de conhecimento com professores. Em comportamentos de alunos que se enquadram exatamente com os que foram apontados durante as aulas de graduação e também em resolução de problemas. A gama de ênfases que tive durante a graduação me auxilia durante a escolha de métodos de intervenções (P19).

Nota-se que assim, como foi mencionado pelo G1 (P1, P5, P6, P8, P9 e P10), que P16 e P19 também destacaram o conhecimento adquirido durante as aulas da graduação, principalmente as de cunho mais prático, como estudos de caso, adaptações e recursos, o que pode indicar que as práticas fomentadas no curso de licenciatura em Educação Especial em tais aspectos estão sendo benéficas para a atuação dos professores.

\section{Comparação entre G1 e G2}

Ao que se refere à comparação entre os grupos, nota-se que G1 e G2 são compostos por amostras que vivenciaram experiências diferenciadas, porém, para se identificar um possível impacto do PIBID, tornou-se relevante optar por um segundo grupo que não participou do programa. Portanto, ao observar e comparar os relatos entre G1 e G2, nota-se que no G1 houve mais relatos quanto às suas práticas atuais, assim como a relevância do ensino colaborativo, quesito não mencionado pelos professores do G2. Em relação ao G2, notou-se o estágio como a experiência relevante para a atuação, assim como o aprendizado no cotidiano e o aprendizado durante as aulas.

\section{Considerações finais}

Podemos apontar a partir desse estudo que o PIBID é um programa que traz impactos positivos nas práticas e profissão dos professores de Educação Especial. Porém, também demostra a importância que os demais aspectos possuem para a formação e atuação de tais profissionais, enfatizando a complementaridade dos programas e projetos durante a 
graduação. Além disso, tal pesquisa mostra a relevância do PIBID na atuação profissional, demostrando que tal programa não traz subsídios somente durante a formação de licenciandos, mas para práticas durante sua profissão, principalmente por se tratar se um programa que visa transformações na qualidade da educação. Desse modo, indicam-se futuras pesquisas que tratem do PIBID com egressos, visto a importância que este programa possui na formação e, como apontado neste estudo, na atuação dos profissionais.

\section{REFERENCIAS}

BATISTA, Bruna Rafaela.; DUARTE, Márcia.; CAMPOS, Juliane Aparecida Paula Perez. Pibid na educação especial: uma experiência de adaptação de atividades para apoio a inclusão escolar. Educação em revista, Marília, n. 2, v. 7, p. 73-84, 2016.

BRASIL. Lei de Diretrizes e Bases da Educação Nacional, n 12.796/13. Brasília: 2013.

BRASIL. Política Nacional de Educação Especial na Perspectiva da Educação Inclusiva. Brasília: MEC, SEESP. 2008.

BRASIL. Lei $\mathbf{n}^{\circ}$. 11.273, de 6 de fevereiro de 2006. Autoriza a concessão de bolsas de estudo e de pesquisa a participantes de programas de formação inicial e continuada de professores para educação básica. República Federativa do Brasil. Brasília, DF, Seção 1. 2006.

BRASÍLIA. Diretoria de formação de professores da Educação Básica-DEB. Relatório de gestão PIBID/Capes. 2013.

BERTÃO, Talita Silva Perussi.; DUARTE, Márcia.; CAMPOS, Juliane Aparecida Canpos. O Pibid da Licenciatura em Educação Especial: reflexões sobre a experiência vivida por uma bolsista. Revista Ensino e Pesquisa, n. 2, v. 13, p. 126-138, 2015.

BRIDI, Jamile Cristina Ajub. Atividade de pesquisa: contribuições da iniciação científica na formação geral do estudante universitário. Revista Olhar de Professor, n. 13, v. 2, p. 349360, 2010.

DUARTE, Márcia.; CAMPOS, Juliane Aparecida Paula Perez.; VILARONGA, Carla Ariela Rios. Experiências do PIBID da licenciatura em Educação Especial da UFSCar. Revista Polyphonía, n. 1, v. 25, p. 65-77, 2014.

FRANCO, Maria Laura Puglisi Barbosa. Análise de conteúdo. Brasília: Plano editora, 2003.

CARVALHO, Renata Nataliana; FUKUARA, Aline; CAMPOS, Juliane Aparecida Paula Perez; DUARTE, Márcia. Experiências de adaptações curriculares no PIBID da Educação Especial. In: VII Congresso Brasileiro de Educação Especial, São Carlos. Anais do VII Congresso Brasileiro de Educação especial, 2016. 
GATTI, Bernardete Angelina. A formação inicial de professores para educação básica: as licenciaturas. Revista USP. São Paulo, n.100, p.33-46, 2013.

GIL, Antônio Carlos. Como elaborar projeto de pesquisa. São Paulo. Atlas, 2002.

KHALED, Ana Paula Aoki Gandur; CAMPOS, Juliane Aparecida Paula Perez; DUARTE, Márcia. Pibid Educação Especial UFSCar e o trabalho colaborativo: relato de experiência. In: VII Congresso Brasileiro de Educação Especial, São Carlos. Anais do VII Congresso Brasileiro de Educação Especial, 2016.

LEVY, Evelyn Talita Silveira; CAMPOS, Juliane Aparecida Paula Perez; GALVANI, Márcia Duarte. Trajetória de iniciação à docência: um caminho progressivamente colaborativo e inclusivo. In: VII Congresso Brasileiro de Educação Especial, São Carlos. Anais do VII Congresso Brasileiro de Educação Especial, 2016.

MENDES, Enicéia Gonçalves; ALMEIDA, Maria Amélia; TOYODA, Cristina Yoshi. Inclusão escolar pela via da colaboração entre Educação Especial e educação regular. Educar em Revista. Setor de Educação da Universidade Federal de Uberlândia (UFU), n. 41, p. 8093, 2011.

MENDES, Angelica da Silveira; MESSERSCHMIDT, Danieli Wayss; PEREIRA, Daiane Flores; SILVA, Giovana Krause; MENEZES, Eliane Costa Pereira. Educação

Especial/UFSM- PIBID: ações do ensino colaborativo na escola inclusiva. In: VI Congresso Brasileiro de Educação Especial, São Carlos. Anais do VI Congresso Brasileiro de Educação especial, 2014.

SANTANA, Maiane Santos Silva. O PIBID e a iniciação docente: um estudo com professores egressos do programa. 176f. Dissertação de mestrado, Programa de pósgraduação em educação, Universidade Federal da Bahia, Salvador, 2015.

NÓVOA, Antônio. Os professores e sua formação. Lisboa: Dom Quixote, 1995.

PIMENTA, Selma Garrido; LIMA, Maria Socorro Lucena. Estágio e docência. São Paulo: Cortez, 2009.

PIBID-UFSCAR. Site Institucional do PIBID UFSCar. Disponível em:

http://www.pibid.ufscar.br/. Acesso em: 16 out. 2017.

PIBID- EDUCAÇÃO ESPECIAL. Subprojeto de Licenciatura em Educação Especial. Universidade Federal de São Carlos. 2013.

CAPES. Portaria n. 46. Regulamento do programa institucional de bolsa de iniciação à docência. 2016. Disponível em:

https://www.capes.gov.br/images/stories/download/legislacao/15042016-Portaria-46Regulamento-PIBID-completa.pdf. Acesso em: 10 mar. 2018.

RIBEIRO, Luis Tavoro Furtado; ARAÚJO, Osmar Hélio Alves. O estágio supervisionado: fios, desafios, movimentos e possibilidades de formação. Revista Ibero-Americana de Estudos em Educação, Araraquara, v. 12, n. 3, p. 1721-1735, 2017. Disponível em: https://doi.org/10.21723/riaee.v.12.n.3.2017.10280. E-ISSN: 1982-5587. 
VERDUM, Priscila Lima. O programa PIBID na avaliação dos pesquisadores do campo educacional: um estudo a partir dos trabalhos do Banco de dissertações e teses da Capes e do Endipe (2010-2012). X Anped Sul, Florianópolis, 2014.

\section{Como referenciar este artigo}

SPINAZOLA, C. de C.; GALVANI, M. D. Impactos do PIBID sobre atuação de professores egressos do curso de Licenciatura em Educação Especial. Revista Ibero-Americana de Estudos em Educação, Araraquara, v. 14, n. 1, p. 293-308, jan./mar., 2019. E-ISSN: 19825587. DOI: 10.21723/riaee.v14i1.10944

Submissão: $23 / 01 / 2018$

Revisões requeridas: 10/04/2018

Aprovação final: $26 / 07 / 2018$ 